\title{
Emotional intelligence and schizophrenia spectrum disorders: a critical review
}

\author{
Inteligência emocional e transtornos do espectro da esquizofrenia: uma revisão \\ crítica da literatura
}

Fernanda de Marzio Pestana Martins, Keila Pereira Leite, Alisson Paulino Trevizol, (D) Julio Ricardo de Souza Noto, Elisa Brietzke (ID)

\begin{abstract}
Introduction: Emotional intelligence (EI) is a theoretical construct postulated by Mayer and Salovey to designate the ability to perceive, understand, use and manage emotions. The study of EI in schizophrenia offers new insights into the disorder's cognitive and functional impacts.

Objectives: To comprehensively review studies analyzing EI impairment in schizophrenia spectrum disorders using standardized instruments.

Methods: Searches were run on MEDLINE/PubMed, Google Scholar, Cochrane, LILACS, Embase, ClinicalTrials.gov and SciELO databases. The only validated instrument used was the Multifactor Emotional Intelligence Scale (MSCEIT). Articles that used all branches of the MSCEIT to assess EI in schizophrenia spectrum disorders and healthy controls were included in the review.

Results: We found 30 articles on this topic. The studies analyzed showed a significant impairment of MSCEIT total score in patients with schizophrenia spectrum disorders when compared to healthy controls. In relation to the MSCEIT branches, understanding of emotions and management of emotions are the most impaired branches.

Conclusion: Since most studies are cross-sectional, it is not possible to establish a cause and effect relationship between EI deficits and schizophrenia spectrum disorders. Therefore, longitudinal studies are needed to establish a clearer relationship between these variables. By so doing, we may be able to intervene for prevention and management of these disorders, aiming at better quality of life for patients.
\end{abstract}

Keywords: Emotional intelligence, schizophrenia, psychotic disorders.

\section{Resumo}

Introdução: Inteligência emocional (IE) é um constructo postulado por Mayer e Salovey para designar a habilidade de perceber, entender, utilizar e gerenciar emoções. O estudo de IE em esquizofrenia oferece novos insights quanto ao impacto deste transtorno em funções cognitivas e funcionais.

Objetivos: Conduzir revisão da literatura que analisa o prejuízo em IE nos transtornos do espectro da esquizofrenia utilizando instrumentos padronizados.

Métodos: Buscas foram realizadas nos bancos de dados MEDLINE/PubMed, Google Scholar, Cochrane, LILACS, Embase, ClinicalTrials.gov e SciELO. O único instrumento validado utilizado foi a Multifactor Emotional Intelligence Scale (MSCEIT). Artigos que utilizaram todas as ramificações da MSCEIT para avaliar IE em transtornos do espectro da esquizofrenia e em controles saudáveis foram incluídos na revisão.

Resultados: Encontramos 30 artigos no tópico estudado. Os estudos analisados mostraram um prejuízo significativo da IE pela MSCEIT em pacientes com transtornos do espectro da esquizofrenia quando comparados com controles saudáveis. Em relação às ramificações da MSCEIT, compreensão das emoções e gerenciamento das emoções foram as ramificações com maior prejuízo.

Conclusão: Devido à maior parte dos estudos serem estudos transversais, não é possível estabelecer uma relação de causa e efeito entre os déficits em IE e transtornos do espectro da esquizofrenia. Portanto, estudos longitudinais são necessários para se estabelecer uma relação mais clara entre essas variáveis. Assim, talvez possamos intervir na prevenção e manejo desses transtornos, para uma melhor qualidade de vida dos pacientes. Descritores: Inteligência emocional, esquizofrenia, transtornos psicóticos. 


\section{Introduction}

According to Mayerand Salovey, emotionalintelligence (EI) is a set of interrelated abilities made up of four dimensions: perception, understanding, management, and use of emotions. ${ }^{1}$ Different explanatory concepts of EI have been translated into different instruments for assessment of this construct. One example is the Mayer and Salovey four-dimensional model which Mayer et al. ${ }^{2}$ used to generate the Multifactor Emotional Intelligence Scale (MEIS) and, more recently, Mayer et al. ${ }^{3}$ used to construct the MSCEIT.

Deficiency of emotional intelligence has been considered a central feature in schizophrenia spectrum disorders and a crucial determinant of functional outcomes according to Fett et al. ${ }^{4}$ This was considered so important that the Emotion Management branch of the MSCEIT was included in the National Institutes of Mental Health Initiative, Measurement and Treatment Research to Improve Cognition in Schizophrenia (MATRICS), as the representative test of social cognition to be evaluated in clinical trials, as reported by Green et al. ${ }^{5}$ and Nuechterlein et al. ${ }^{6}$

The objective of this review was to comprehensively assess the literature on EI in Schizophrenia spectrum disorders, aiming to describe and critically evaluate the extent to which this concept could be clinically useful.

\section{Methods}

For this review, searches for relevant articles were run on the MEDLINE/PubMed, Google Scholar, Cochrane, LILACS, Embase and SciELO databases.

Searches were performed during October of 2017 for studies published from inception to 2017 and used the following terms for MEDLINE/PubMed: ("Emotional Intelligences" OR "Intelligence, Emotional" OR "Intelligences, Emotional" OR "Social Intelligence" OR "Intelligence, Social" OR "Intelligences, Social" OR "Social Intelligences") AND (MSCEIT OR "Mayer-Salovey-Caruso Emotional Intelligence Test") AND ("Schizophrenias" OR "SchizophrenicDisorders"OR "Disorder, Schizophrenic"OR "Disorders, Schizophrenic" OR "Schizophrenic Disorder" OR "Schizophrenia" OR "Schizophrenia Spectrum and Other Psychotic Disorders" OR "Schizophrenia, Paranoid" OR "Schizophrenia, Disorganized" OR "Schizophrenia, Childhood" OR "Schizophrenia, Catatonic").

The reference lists of papers included were manually searched for additional pertinent references. The abstracts of all the articles identified were read by two authors (KPL and FDMPM) to select those that would be included in our analysis. After we had selected articles on the basis of their abstracts, the full texts were read by three authors, to ensure the best evaluation possible.

We searched for relevant original articles in English, Portuguese or Spanish that used standardized methods to access Emotional Intelligence in the manner that this construct was described by Mayer and Solomon. We were specifically searching for studies involving adult populations that compared EI between subjects with schizophrenia spectrum disorders and healthy controls or subjects with different mental disorders.

\section{Results}

The first issue in this review was related to the instrument. The only instrument that appropriately evaluated the EI as a construct was the MSCEIT. Because of this, for the purpose of this study we focused only on articles that used MSCEIT to evaluate EI. There are two main reasons for this choice: first, the Mayer and Salovey model's theoretical approach is more tenable than those of other models, in the researchers' opinion. Second, MSCEIT is currently the only ability test that covers all four dimensions of EI. Third, as already explained, the MSCEIT has good validity, which has not been observed for other instruments. ${ }^{7}$

The search returned 30 articles assessing associations between emotional abilities and schizophrenia spectrum disorders. After reading abstracts and full text articles, 19 were selected because they reported using all four branches of the MSCEIT to evaluate EI scores.

Table 1 lists the studies, describing the populations studied and their study designs, main findings, and limitations.

\section{Schizophrenia-spectrum disorders}

Social cognition has been considered a core construct in the cognitive domain of schizophrenia psychopathology and a crucial determinant of functional outcomes. ${ }^{4}$ This was considered to be so important that the Emotion Management branch of MSCEIT was included by the National Institutes of Mental Health Initiative, Measurement and Treatment Research to Improve Cognition in Schizophrenia (MATRICS), as the representative test for social cognition to be evaluated in clinical trials. 5,6

The studies reviewed found significant deficiencies in the overall MSCEIT performance score and also in scores for each of its four components in patients with schizophrenia spectrum disorders, when compared to healthy subjects. Kee et al.,19 Dawson et al. ${ }^{11}$ and Mao et al. ${ }^{21}$ found that understanding and management of emotions were the most deficient. Furthermore, 
Table 1 - Findings of research investigating relationships between EI and schizophrenia spectrum disorders

\begin{tabular}{|c|c|c|c|c|c|}
\hline Disorder & Study & Study design & Sample size & Results & Study limitations and bias \\
\hline Schizophrenia & Albacet $^{8}$ & Cross-sectional & $\begin{array}{l}37 \text { clinical subjects }+37 \\
\text { first degree relatives }+ \\
37 \text { healthy controls }\end{array}$ & $\begin{array}{l}\text { Impairment in MSCEIT score for } \\
\text { the clinical sample and for the first } \\
\text { degree relatives. }\end{array}$ & $\begin{array}{l}\text { - Small sample. } \\
\text { - Groups were not well matched for age, } \\
\text { gender and IQ. }\end{array}$ \\
\hline Schizophrenia & Brambilla $^{9}$ & Clinical Trial & $\begin{array}{l}31 \text { schizophrenia } \\
\text { patients }\end{array}$ & $\begin{array}{l}\text { They found that 4-months' } \\
\text { treatment with intranasal oxytocin } \\
\text { was related to improvement in the } \\
\text { understanding emotions branch of } \\
\text { MSCEIT. }\end{array}$ & $\begin{array}{l}\text { - Small, mainly male and young sample. } \\
\text { - Unable to tell if the effects were seen } \\
\text { only in social cognition or in general } \\
\text { cognition as well. }\end{array}$ \\
\hline Schizophrenia & Cicero $^{10}$ & Cross-sectional & $\begin{array}{l}45 \text { schizophrenia } \\
\text { patients }+28 \text { healthy } \\
\text { controls }\end{array}$ & $\begin{array}{l}\text { They found that the clinical sample } \\
\text { had worse MSCEIT performance } \\
\text { when compared to controls. } \\
\text { Positive symptoms were related to } \\
\text { poorer perception and management } \\
\text { of emotions. }\end{array}$ & $\begin{array}{l}\text { - Small sample. } \\
\text { - Unable to establish causal effects. }\end{array}$ \\
\hline Schizophrenia & Dawson $^{11}$ & Cross-sectional & $\begin{array}{l}20 \text { clinical subjects }+20 \\
\text { healthy controls }\end{array}$ & $\begin{array}{l}\text { Impairment in MSCEIT score, social } \\
\text { functioning and Neurocognition for } \\
\text { the clinical sample. }\end{array}$ & $\begin{array}{l}\text { - Small sample. } \\
\text { - Samples were not well matched for } \\
\text { premorbid intelligence. }\end{array}$ \\
\hline Schizophrenia & Eack $^{12}$ & $\begin{array}{l}\text { Cross-sectional } \\
\text { (validity) }\end{array}$ & $\begin{array}{l}64 \text { clinical subjects ( } 37 \\
\text { with schizophrenia }+ \\
23 \text { with schizoaffective } \\
\text { disorder }+4 \text { with } \\
\text { schizophreniform } \\
\text { disorder) }\end{array}$ & $\begin{array}{l}\text { They report that the MSCEIT has } \\
\text { adequate internal consistency and } \\
\text { reliability to evaluate the sample. } \\
\text { They also found a shift in the EI } \\
\text { factor structure in the sample when } \\
\text { compared to healthy subjects. }\end{array}$ & $\begin{array}{l}\text { - Small sample. } \\
\text { - Patients were selected from a clinical } \\
\text { trial of CET. }\end{array}$ \\
\hline Schizophrenia & Eack $^{13}$ & Retrospective & $\begin{array}{l}64 \text { clinical subjects } \\
\text { (same as the previous } \\
\text { study - Eack et al. }{ }^{12} \text { ) }+ \\
\text { normative sample with } \\
2563 \text { subjects }\end{array}$ & $\begin{array}{l}\text { They confirm the previous finding } \\
\text { of a shift in the factor structure of } \\
\text { EI in patients with schizophrenia. }\end{array}$ & $\begin{array}{l}\text { - Small clinical sample. } \\
\text { - Absence of demographically-matched } \\
\text { controls known to be free from mental } \\
\text { disorders. }\end{array}$ \\
\hline Schizophrenia & Eack $^{14}$ & $\begin{array}{l}\text { Randomized } \\
\text { controlled trial }\end{array}$ & $\begin{array}{l}58 \text { early-course } \\
\text { outpatients with } \\
\text { schizophrenia spectrum } \\
\text { disorders }\end{array}$ & $\begin{array}{l}\text { They found CET to be an effective } \\
\text { approach for improving cognitive } \\
\text { deficits in the sample. }\end{array}$ & - Small sample. \\
\hline Schizophrenia & Eack $^{15}$ & Clinical trial & $\begin{array}{l}58 \text { early-course } \\
\text { schizophrenia } \\
\text { outpatients }\end{array}$ & $\begin{array}{l}\text { They found CET had an impact on } \\
\text { EI measures and correlated this } \\
\text { result with the functional outcome. }\end{array}$ & $\begin{array}{l}\text { - Small sample. } \\
\text { - Unable to discard type I error. }\end{array}$ \\
\hline Schizophrenia & Frajo-Apor ${ }^{16}$ & Cross-sectional & $\begin{array}{l}56 \text { paranoid } \\
\text { schizophrenia patients } \\
\text { and } 84 \text { healthy controls }\end{array}$ & $\begin{array}{l}\text { They found that the clinical } \\
\text { sample had poorer EI than the } \\
\text { controls. They found this effect was } \\
\text { mediated by non-social cognition. }\end{array}$ & $\begin{array}{l}\text { - They suggest that more tools could be } \\
\text { used to assess EI. } \\
\text { - Different treatments for different } \\
\text { patients in the clinical sample. } \\
\text { - Some of the patients were symptomatic } \\
\text { during the tests. }\end{array}$ \\
\hline Schizophrenia & Frajo-Apor ${ }^{17}$ & Cross-sectional & $\begin{array}{l}58 \text { schizophrenia } \\
\text { outpatients and } 60 \\
\text { bipolar disorder I } \\
\text { outpatients }\end{array}$ & $\begin{array}{l}\text { They demonstrate that the } \\
\text { schizophrenia sample performed } \\
\text { worse on the MSCEIT when } \\
\text { compared to the bipolar disorder } \\
\text { patients (except for the emotion } \\
\text { perception branch). They also } \\
\text { correlated the difference to non- } \\
\text { social cognition. }\end{array}$ & $\begin{array}{l}\text { - They used the BACS to evaluate } \\
\text { non-social cognition in both groups, } \\
\text { although it is only validated for } \\
\text { schizophrenia samples. } \\
\text { - Some patients were not in full } \\
\text { remission. }\end{array}$ \\
\hline Schizophrenia & Green $^{18}$ & Cross-sectional & $\begin{array}{l}\text { - } 50 \text { individuals } \\
\text { with prodromal } \\
\text { risk syndrome for } \\
\text { psychosis }+34 \\
\text { demographically } \\
\text { comparable controls. } \\
\text { - } 81 \text { first-episode } \\
\text { schizophrenia }+46 \\
\text { demographically } \\
\text { comparable controls. } \\
\text { - } 53 \text { chronic } \\
\text { schizophrenia }+47 \\
\text { demographically } \\
\text { comparable controls. }\end{array}$ & $\begin{array}{l}\text { They found the clinical samples } \\
\text { to have impairment on general } \\
\text { MSCEIT performance. There was } \\
\text { no significant difference in MSCEIT } \\
\text { performance during the different } \\
\text { phases of illness, except for the } \\
\text { perception of emotions branch. }\end{array}$ & $\begin{array}{l}\text { - Some patients were using antipsychotic } \\
\text { medications. } \\
\text { - The sample was mainly young. } \\
\text { - Unable to establish causal effects. }\end{array}$ \\
\hline Schizophrenia & $\mathrm{Kee}^{19}$ & Cross-sectional & $\begin{array}{l}50 \text { schizophrenia and } 39 \\
\text { non-psychiatric controls }\end{array}$ & $\begin{array}{l}\text { The clinical sample had poorer EI } \\
\text { than controls. The MSCEIT score } \\
\text { was worse in patients with negative } \\
\text { symptoms and those with poorer } \\
\text { community functioning. }\end{array}$ & $\begin{array}{l}\text { - Small sample. } \\
\text { - Unable to discard type I error. } \\
\text { - Unable to evaluate if the severity of } \\
\text { symptoms was related to the chronicity } \\
\text { of disease, to emotional traits or to the } \\
\text { long-term exposure to antipsychotic } \\
\text { medications. }\end{array}$ \\
\hline
\end{tabular}


Dawson et al. ${ }^{11}$ also reported neurocognitive and social functioning impairments compared to healthy controls.

In general, we review and report the validity and reliability of MSCEIT for assessment of individuals with schizophrenia, presence of EI deficits in comparison to healthy controls and correlations with severity of symptoms. In accordance with previous studies, Eack et al. ${ }^{12}$ and Tabak et al. ${ }^{28}$ observed small to medium correlations with symptom severity, stable at various stages of the disease.
Despite the validity of the MSCEIT for assessing emotional intelligence in individuals with mental disorders, a need was highlighted for further development of the test to improve social cognition assessment in patients with schizophrenia. ${ }^{12}$ Additionally, divergent measures were observed associated with neurocognitive and psychopathological functions in this population. Because of this, more research is needed into a possible latent factor of social cognition in schizophrenia that is not captured by the MSCEIT.

Table 1 (cont.)

\begin{tabular}{|c|c|c|c|c|c|}
\hline Disorder & Study & Study design & Sample size & Results & Study limitations and bias \\
\hline Schizophrenia & $\operatorname{Lin}^{20}$ & Cross-sectional & $\begin{array}{l}174 \text { schizophrenia } \\
\text { and } 20 \text { schizoaffective } \\
\text { disorder }\end{array}$ & $\begin{array}{l}\text { They found MSCEIT to have a two- } \\
\text { factor structure in the schizophrenia } \\
\text { sample. Factor } 1 \text { broadly } \\
\text { associated with the regulation } \\
\text { and management of emotions and } \\
\text { factor } 2 \text { related with facial emotion } \\
\text { perception. }\end{array}$ & - Unable to establish causal effects. \\
\hline Schizophrenia & $\mathrm{Mao}^{21}$ & Cross-sectional & $\begin{array}{l}76 \text { schizophrenia and } \\
738 \text { healthy controls }\end{array}$ & $\begin{array}{l}\text { They found MSCEIT-TC (Traditional } \\
\text { Chinese Version) to be reliable and } \\
\text { valid for assessment of EI in the } \\
\text { schizophrenic sample. } \\
\text { When comparing the groups, they } \\
\text { found EI impairment in the clinical } \\
\text { sample. The impact was more } \\
\text { important for the Understanding } \\
\text { Emotions and Managing Emotions } \\
\text { branches. }\end{array}$ & $\begin{array}{l}\text { - Unable to establish the causal effects. } \\
\text { - Cross-cultural assessment of EI. }\end{array}$ \\
\hline Schizophrenia & McCleery 22 & $\begin{array}{l}\text { Prospective } \\
\text { observational } \\
\text { cohort }\end{array}$ & 41 clinical subjects & $\begin{array}{l}\text { The results showed that there } \\
\text { were no changes in emotional } \\
\text { abilities over the } 5 \text {-year period. } \\
\text { Furthermore, EI had no significant } \\
\text { longitudinal influence on community } \\
\text { functioning after five years. }\end{array}$ & $\begin{array}{l}\text { - Small sample size. } \\
\text { - Absence of healthy controls. }\end{array}$ \\
\hline Schizophrenia & O'Reilly ${ }^{23}$ & $\begin{array}{l}\text { Prospective } \\
\text { observational } \\
\text { cohort }\end{array}$ & $\begin{array}{l}89 \text { schizophrenia ( } 10 \\
\text { violent) }\end{array}$ & $\begin{array}{l}\text { The violent group performed worse } \\
\text { on MSCEIT than the nonviolent } \\
\text { group. The study also found that } \\
\text { the severity of symptoms had a } \\
\text { strong inverse correlation with } \\
\text { MSCEIT performance. }\end{array}$ & $\begin{array}{l}\text { - The sample was in a secure forensic } \\
\text { environment. } \\
\text { - The sample was majority male. }\end{array}$ \\
\hline Schizophrenia & Wojtalik ${ }^{24}$ & Cross-sectional & $\begin{array}{l}51 \text { early-course, } \\
\text { stabilized schizophrenia } \\
\text { or schizoaffective } \\
\text { disorder patients. }\end{array}$ & $\begin{array}{l}\text { Patients with lower scores for } \\
\text { Facilitating, Managing and Using } \\
\text { emotions exhibited reduced } \\
\text { gray matter density in the left } \\
\text { parahippocampal gyrus. Those } \\
\text { with poorer results in Facilitating } \\
\text { and Managing emotions exhibited } \\
\text { reduced right posterior cingulate } \\
\text { gray matter density. }\end{array}$ & $\begin{array}{l}\text { - Moderate sample size. } \\
\text { - Absence of healthy controls. } \\
\text { - Unable to evaluate causal effects. }\end{array}$ \\
\hline Schizophrenia & Hurtado 26 & Cross-sectional & $\begin{array}{l}19 \text { schizophrenia } \\
\text { (17 paranoid and } 2 \\
\text { indefinite subtype), } 15 \\
\text { borderline personality } \\
\text { disorder and } 18 \text { healthy } \\
\text { controls. }\end{array}$ & $\begin{array}{l}\text { Both groups of patients exhibited } \\
\text { significantly lower performance } \\
\text { in terms of total MSCEIT scores. } \\
\text { Schizophrenia patients exhibited } \\
\text { impairment in perception, } \\
\text { facilitation and understanding of } \\
\text { emotions in relation to the control } \\
\text { group. }\end{array}$ & $\begin{array}{l}\text { - Unable to evaluate causal effects. } \\
\text { - Small sample size and exploratory } \\
\text { nature. }\end{array}$ \\
\hline
\end{tabular}

Adapted from Kun et al. ${ }^{27}$

BACS = Brief Assessment of Cognition in Schizophrenia; CET = Cognitive Enhancement Therapy; EI = emotional intelligence; IQ = intelligence quotient; MSCEIT = Multifactor Emotional Intelligence Scale. 
In 64 outpatients with schizophrenia, schizoaffective disorder and schizophreniform disorder, Eack et al. investigated the credibility of the MSCEIT scale in relation to the domains of social cognition. ${ }^{12}$ It has been observed that the scale is reliable and valid for this type of evaluation, however, it is unable to widely evaluate the components of social cognition associated with the functional performance of these patients. This is because estimated discriminant and concurrent validity as well as estimated convergent validity suggest that MSCEIT did not correlate with measures of psychopathology and neurocognitive functioning. Therefore, the MSCEIT would not correspond to a behavioral evaluation of social cognition and further investigation is needed into possible latent factors associated with this divergence. They found a two-factor MSCEIT structure in patients with schizophrenia that is different from two or four factor structures observed for healthy controls. In healthy individuals, MSCEIT has a four-factor structure, which includes perception, facilitation, understanding and management of emotions, as reported by Mayer and Salovey. ${ }^{1}$ These, in turn, can be grouped into a two-factor structure, representing highlevel and low-level emotional intelligence processing. According to Mayer et al., in healthy individuals, the lowlevel "experiential" factor contains both perception and facilitation, while the "strategic" high level factor contains understanding and management of emotions. ${ }^{3}$ In contrast, in subjects with schizophrenia spectrum disorders, the composition of the "experiential" and "strategic" factors is (I) perception and understanding and (II) facilitation and management, respectively, as found by Eack et al. ${ }^{12}$ and Lin et al. ${ }^{20}$ It can be noted that this population's EI is structured differently from that of healthy controls, since facilitation and understanding of emotions are at different levels of processing.

Eack et al. used multi-group confirmatory factor analysis to test factorial invariance of the MSCEIT across schizophrenia. ${ }^{13}$ The sample comprised patients with schizophrenia spectrum disorders $(n=64)$ and two normative samples $(n=2099$ and $n=451)$. The schizophrenia sample was the same as in the previous Eack et al. ${ }^{12}$ study and the normative sample was taken from two previous investigations of MSCEIT, one by Mayer et al. ${ }^{3}$ with 2112 adults and the other by Palmer et al. ${ }^{29}$ with 451 adults. Both normative samples were selected from the general population, in which the prevalence of schizophrenia is approximately $3 \%$. They found that the factor structure of the MSCEIT was significantly different between the schizophrenia and normative samples, confirming the results of the previous study.

Eack et al. conducted a prospective study to evaluate whether a two-year trial of cognitive enhancement therapy (CET) revealed improvements in social function for patients in early-course schizophrenia. ${ }^{14}$ They quote a previous Eack et al. study the results of which had demonstrated improvement in EI measures with a two-year trial of CET. ${ }^{15}$ The sample comprised 58 outpatients with early-course schizophrenia $(\mathrm{N}=38)$ or schizoaffective disorder $(\mathrm{N}=20)$. They found improvement in neurocognition and the emotion management branch of the MSCEIT to be significantly related to improved functional outcome in the sample. Neurocognitive improvement, primarily in executive functioning, and social-cognitive change in emotion management also mediated the robust effects of CET on functioning.

With regard to analysis of images obtained by magnetic resonance, one study found that patients with poor performance in MSCEIT total scores and also those with low scores for understanding, management, and facilitation of emotions, exhibited significant reductions in the gray matter density of the left parahippocampal gyrus. ${ }^{24}$ Additionally, poor performance in handling and facilitation of emotions was significantly associated with reduced gray matter density of the right posterior cingulate gyrus.

Among patients with schizophrenia spectrum disorders, higher scores on the MSCEIT were reported in women $(p<0.05)$ and patients with a higher educational level $(p<0.05)$. Additionally, Eack et al. reported an inverse correlation between test performance and disease duration. ${ }^{12}$ Kee et al. also observed a significant correlation between lower MSCEIT scores and negative and disorganized symptoms, as well as poorer functioning in the community. ${ }^{19}$ Interestingly, individuals with schizophrenia had subjective deficits in EI compared to healthy controls. A better EI result in this group of patients was associated with a higher probability of living independently, as reported by Tabak et al. ${ }^{28}$

In another analysis, a group of researchers administered the MSCEIT to three groups representing the different phases of schizophrenia: prodromal, first episode and chronic schizophrenia. ${ }^{18}$ A demographically comparable healthy control group was selected for each of these groups. Impairments were observed in all three clinical groups when compared to their respective controls. Additionally, there was a significant phase effect in relation to the MSCEIT perception of emotions branch, with a decline in both later disease stage groups. However, there was no evidence of worsening or improvement of emotional abilities with disease progression. Thus, as the impairment also applies to the earlier phases of the disease, it is suggested that daily functioning relationships that have been established for the chronic phase can also be applied to these initial phases. 
In common with Green et al., ${ }^{18}$ McCleery et al. also investigated the relationship between the emotional abilities of patients with schizophrenia and the chronicity of the disease. ${ }^{22}$ The MSCEIT scale was administered to 41 patients with schizophrenia at baseline and after about five years. Additionally, the Role Functioning Scale (RFS) was used to evaluate longitudinal associations between EI and community functioning. The results showed that there were no changes in emotional abilities over the period. Furthermore, EI had no significant longitudinal influence on community functioning after five years. However, the study reports that, according to much of the literature, there is an association between EI and community functioning, only cross-sectional, rather than longitudinal. Therefore, the study suggests that the EI of patients with schizophrenia, rather than having longterm consequences, exhibits short-term influences.

Heterogeneity of scores on the MSCEIT was observed in schizophrenia groups. O'Reilly et al. ${ }^{23}$ prospectively evaluated a group of 76 individuals with schizophrenia and 13 with schizoaffective disorder over a period of 12 months to test the influence of EI on risk of violence. Using multivariate analyses, the variables neurocognition and social cognition accounted for $34 \%$ of the variance in violent episodes after controlling for age and gender. Scores on the MSCEIT were significantly lower for the violent group compared to non-violent subjects and produced the largest effect size. Prevalence of violence (HCR-Score), symptoms (PANSS Total Score), cognition (MSCEIT) and social functioning (SOFAS) acted as independent variables in the relationship between violence and neurocognition.

Albacete et al. studied a sample comprising subjects with schizophrenia, healthy controls and first-degree relatives of individuals with schizophrenia. ${ }^{8}$ The authors reported significantly lower MSCEIT total scores, and also lower perception of emotions scores, in firstdegree relatives in comparison to healthy controls. The strongest positive correlations between first-degree relatives and controls were the measures of executive function, processing speed, and general intelligence.

As in most of the studies, EI assessments of patients with schizophrenia spectrum disorders reveal some impairment in one or more of the four emotional abilities assessed by the MSCEIT. Brambilla, et al. investigated not only this impairment, but also the influence of oxytocin on it. ${ }^{9}$ Thirty-one schizophrenic patients were randomized to a placebo group or to receive oxytocin. In comparison with the placebo group, it was found that oxytocin had a significant effect on understanding of emotions as assessed by the MSCEIT. It was therefore suggested that oxytocin supports the ability to understand emotions as well as their transitions through relationships and their emotional meanings. Additionally, a trend was identified for the significance of a treatment effect on the strategic domain of emotional abilities, i.e., not only would there be an increase in the ability to understand emotions, but also in the ability to manage them.

Cicero et al. administered the MSCEIT scale to 48 people with schizophrenia and 28 healthy controls and found lower MSCEIT scores among individuals with high scores on the Inventory of Psychotic-Like Anomalous SelfExperiences (IPASE), in comparison to the control group, as well as impaired ability to use emotions. ${ }^{10}$ However, the severity of positive symptoms was associated with deficits in the perception and management of emotions branches. On the other hand, negative symptoms were not associated with MSCEIT scores. Thus, by removing shared variance with positive symptoms, this study identified the importance of anomalous self-experiences (ASEs) to explaining emotional processing in patients with schizophrenia. However, ASEs do not fully explain the deficits in the emotional abilities of individuals with schizophrenia because the positive symptoms exhibited significant relationships even after the removal of the shared variance with ASEs.

In addition to investigating the emotional intelligence of patients with schizophrenia, Hurtado et al. also evaluated patients with borderline personality disorder (BPD) using three groups: 19 patients with schizophrenia (17 paranoid and the other 2 with the indefinite subtype), 15 patients with BPD and 18 healthy controls. ${ }^{26}$ Both groups of patients exhibited a significantly lower performance in terms of total MSCEIT score when compared to the control group. With regard to MSCEIT branches, patients with schizophrenia exhibited impairments in perception, facilitation, and understanding of emotions in relation to the control group, while those with BPD only exhibited impairment in perception and understanding of emotions.

Using a mediation analysis, Frajo-Apor et al. ${ }^{16}$ concluded that the mediating effect of non-social cognition is almost entirely responsible for the difference in total MSCEIT score between patients with schizophrenia and controls. Subjects exhibited significantly lower levels of EI and non-social cognition compared to healthy controls. After adjustment for education and Brief Assessment of Cognition in Schizophrenia (BACS) composite score, only the difference for the "emotion management" group (and therefore the "strategic" part of MSCEIT) remained statistically significant, while statistical significance was lost for the other branches of MSCEIT (perception, facilitation, and understanding of emotions). Thus, mediation analysis revealed that the difference between patients with schizophrenia and 
controls over MSCEIT total score was almost entirely attributable to the mediating effect of non-social cognition. Tso et al. suggested that compromised visual integration was a significant predictor of low EI scores, mainly due to a reduction in the perception of ocular contact. ${ }^{25}$

Frajo-Apor et al. ${ }^{17}$ used MSCEIT to compare EI between two clinical groups: clinically stable outpatients with schizophrenia or bipolar I disorder. They also correlated the results to the mediating effect of nonsocial cognition, which was assessed by the Brief Assessment of Cognition in Schizophrenia (BACS). The sample was composed of 58 schizophrenia and 60 bipolar outpatients. They demonstrated that schizophrenia patients achieved a significantly lower score in almost all MSCEIT branches when compared to the bipolar sample. The MSCEIT scores were only similar between both groups for the emotion perception branch. The schizophrenia group demonstrated significantly worse BACS scores. The authors then adjusted the EI results for BACS scores and the statistical significance was lost for all MSCEIT branches. They therefore concluded that schizophrenia patients have worse EI performance and that non-social cognition has an effect on EI scores.

\section{Discussion}

Overall, the findings of this review indicate that individuals with schizophrenia spectrum disorders have poor performance in EI assessed by MSCEIT compared to healthy controls and that these deficits could be related to the severity of symptoms. It was observed that both global EI and the score for each of the scale's dimensions are decreased in most disorders studied. These findings were consistent with the expected results. Lower EI scores are related to worse psychic wellness and possibly to a higher risk of developing mental disorders.

There are some studies indicating that the emotional intelligence of patients with schizophrenia spectrum disorders is structured differently from that of healthy controls in terms of EI processing levels. In controls, the "experiential" factor contains both perception and facilitation and the "strategic" factor contains understanding and management of emotions. In contrast, in subjects with schizophrenia spectrum disorders, the composition of the "experiential" and "strategic" factor composition is (I) perception and understanding and (II) facilitation and management, respectively as reported by Eack et al. ${ }^{12}$ and Lin et al. ${ }^{20}$ Furthermore, our review found that, in general, these patients demonstrated deficits in understanding and management of emotions in particular, that is, in the "strategic" sector of emotional intelligence (high-level thought processing), according to Eack et al. ${ }^{12}$ Our results are consistent with the prior findings of Henry et al., ${ }^{30}$ who reported aberrant emotional expression (i.e., reduced amplification of an experienced emotion) in schizophrenia in comparison to control participants. These findings indicate that individuals with schizophrenia exhibit impairments in their understanding of blends and changes between and among emotions, as well as their regulation of emotions in everyday life as reported by Kee et al. ${ }^{19}$

Interestingly, it is possible to improve the strategic skills of these schizophrenic patients with the use of certain drugs, such as oxytocin, for example. Therefore, new perspectives are provided in relation to improvement of EI of patients with schizophrenia and perhaps their social functioning. ${ }^{9}$ Two studies investigated the EI behavior of these patients throughout the progression of the disease and found no worsening or improvement of emotional abilities. Thus, it is suggested that the consequences of EI damage in people with schizophrenia spectrum disorders may be more short-term than in social functioning in the long run according to Green et al. $^{18}$ and McCleery et al. ${ }^{22}$ Another intervention, CET, also demonstrated improvement in MSCEIT scores and the functional outcomes of schizophrenic patients. ${ }^{15}$ This intervention offers new perspectives on schizophrenia treatment approaches. However, research in this field is still incipient.

Additionally, an interesting result was observed by Frajo-Apor et al. when comparing schizophrenia and bipolar samples: the schizophrenia patients had better MSCEIT scores. ${ }^{17}$ However, none of the other studies compared these two mental disorders, so more research is necessary to clarify this correlation.

\section{Limitations and future research directions}

Most of the items that made up this review are analytical case-control studies, which detected changes in EI scores in subjects with schizophrenia spectrum disorders and healthy controls. Thus, confirmation of a causal relationship between low EI scores and the presence of a schizophrenia spectrum disorder is not possible. Additionally, the fact that not all studies regard intellectual ability as a variable to be investigated is also a limitation. According to Copestake et al., ${ }^{31}$ this is because the negative associations found between EI scores and mental disorders in most studies may be more related to intellectual rather than emotional impairment. 
Another limitation of the present study is the selection of MSCEIT as the only instrument for evaluation of EI, since this restriction caused the exclusion of articles that used other instruments, such as the Bar-On EQI by Bar-On, ${ }^{32}$ the Trait Meta-Mood Scale (TMMS) by Salovey et al. $^{33}$ and the Emotional Intelligence Scale (EIS) by Schutte et al. ${ }^{34}$ Inconsistencies between instruments could be considered a consequence of the lack of a uniform definition of the construct, an aspect that should be explored further.

Thus, further longitudinal studies should be conducted to elucidate whether there is a causeand-effect relationship between EI and schizophrenia spectrum disorder. New interventions for prevention of mental disorders and enhancement of quality of life can be designed following these studies. Additionally, future studies should assess EI using more than one instrument, enabling broader interpretations of EI. Differentiation between negative and positive emotions and evaluation of EI over a certain time period should also be included in future studies. ${ }^{7}$

\section{Acknowledgements}

Keila Pereira Leite receives a scholarship from Conselho Nacional de Desenvolvimento Científico e Tecnológico (CNPq). Elisa Brietzke is supported by Coordenação de Aperfeiçoamento de Pessoal de Nível Superior (CAPES), CNPq, Fundação de Amparo à Pesquisa do Estado de São Paulo (FAPESP), and by a L'Oreal/UNESCO/Brazilian Academy of Science for Women in Science Award.

\section{Disclosure}

No conflicts of interest declared concerning the publication of this article.

\section{References}

1. Mayer JD, Salovey P. What is emotional intelligence? In: Salovey $P$, Sluyter DJ, editors. Emotional development and emotional intelligence: Educational implications. New York: BasicBooks; 1997. p.3-34.

2. Mayer JD, Caruso D, Salovey P. Emotional intelligence meets traditional standards for an intelligence. Intelligence. 1999;27:267-98.

3. Mayer JD, Salovey P, Caruso DR, Sitarenios G. Measuring emotional intelligence with the MSCEIT V2.0. Emotion. 2003;3:97-105.

4. Fett AK, Viechtbauer $W$, Dominguez MD, Penn DL, van Os J, Krabbendam $\mathrm{L}$. The relationship between neurocognition and social cognition with functional outcomes in schizophrenia: a meta-analysis. Neurosci Biobehav Rev. 2011;35:573-88.

5. Green MF, Olivier B, Crawley JN, Penn DL, Silverstein S. Social cognition in schizophrenia: recommendations from the measurement and treatment research to improve cognition in schizophrenia new approaches conference. Schizophr Bull. 2005;31:882-7.

6. Nuechterlein KH, Green MF, Kern RS, Baade LE, Barch DM, Cohen JD, et al. The MATRICS Consensus Cognitive Battery, part 1: test selection, reliability, and validity. Am J Psychiatry. 2008;165:20313.

7. Hertel J, Schutz A, Lammers $\mathrm{CH}$. Emotional intelligence and mental disorder. J Clin Psychol. 2009;65:942-54.

8. Albacete A, Bosque C, Custal N, Crespo JM, Gilabert E, Albiach A, et al. Emotional intelligence in non-psychotic first-degree relatives of people with schizophrenia. Schizophr Res. 2016;175:103-8.

9. Brambillaa M, Cotellia M, Manentia R, Daganib J, Sistic D, Rocchic $M$, et al. Oxytocin to modulate emotional processing in schizophrenia: A randomized, double-blind, cross-over clinical trial. Eur Neuropsychopharmacol. 2016;26:1619-28.

10. Cicero DC, Klaunig MJ, Trask CL, Neis AM. Anomalous selfexperiences and positive symptoms are independently associated with emotion processing deficits in schizophrenia. Schizophr Res. 2016;176:456-61.

11. Dawson S, Kettler L, Burton C, Galletly C. Do people with schizophrenia lack emotional intelligence? Schizophr Res Treatment. 2012;2012:495174.

12. Eack SM, Greeno CG, Pogue-Geile MF, Newhill CE, Hogarty GE, Keshavan MS. Assessing social-cognitive deficits in schizophrenia with the Mayer-Salovey-Caruso Emotional Intelligence Test. Schizophr Bull. 2010;36:370-80.

13. Eack SM, Pogue-Geile MF, Greeno CG, Keshavan MS. Evidence of factorial variance of the Mayer-Salovey-Caruso emotional intelligence test across schizophrenia and normative samples. Schizophr Res. 2009;114:105-9.

14. Eack SM, Pogue-Geile MF, Greeno CG, Greenwald DP, Hogarty SS, Keshavan MS. Mechanisms of functional improvement in a two-year trial of cognitive enhancement therapy for early schizophrenia. Psychol Med. 2011;41:1253-61.

15. Eack SM, Greenwald DP, Hogarty SS, Cooley SJ, DiBarry AL, Montrose DM, et al. Cognitive enhancement therapy for earlycourse schizophrenia: effects of a two-year randomized controlled trial. Psychiatr Serv. 2009;60:1468-76.

16. Frajo-Apor B, Pardeller S, Kemmler G, Welte AS, Hofer A Emotional intelligence deficits in schizophrenia: The impact of non-social cognition. Schizophr Res. 2016;172:131-6.

17. Frajo-Apor B, Kemmler $G$, Pardeller $S$, Plass $T$, Mühlbacher $M$, Welte AS, et al. Emotional intelligence and non-social cognition in schizophrenia and bipolar I disorder. Psychol Med. 2017;47:35-42.

18. Green MF, Bearden CE, Cannon TD, Fiske AP, Hellemann GS, Horan WP, et al. Social cognition in schizophrenia, part 1: performance across phase of illness. Schizophr Bull. 2012;38:854-64.

19. Kee KS, Horan WP, Salovey P, Kern RS, Sergi MJ, Fiske AP, et al. Emotional intelligence in schizophrenia. Schizophr Res. 2009;107:61-8.

20. Lin YC, Wynn JK, Hellemann G, Green MF. Factor structure of emotional intelligence in schizophrenia. Schizophr Res. 2012;139:78-81.

21. Mao WC, Chen LF, Chia $\mathrm{CH}$, Line $\mathrm{CH}$, Kaof YC, Hsug WY, et al. Traditional Chinese version of the Mayer Salovey Caruso Emotional Intelligence Test (MSCEIT-TC): its validation and application to schizophrenic individuals. Psychiatry Res. 2016;243:61-70.

22. McCleery A, Lee J, Fiske AP, Ghermezi L, Hayata JN, Hellemann GS, et al. Longitudinal stability of social cognition in schizophrenia: A 5-year follow-up of social perception and emotion processing. Schizophr Res. 2016;176:467-72.

23. O'Reilly K, Donohoe G, Coyle C, O'Sullivan D, Rowe A, Losty $M$, et al. Prospective cohort study of the relationship between neuro-cognition, social cognition and violence in forensic patients with schizophrenia and schizoaffective disorder. BMC psychiatry. 2015;15:155.

24. Wojtalik JA, Eack SM, Keshavan MS. Structural neurobiological correlates of Mayer-Salovery-Caruso Emotional Intelligence Test performance in early course schizophrenia. Prog Neuropsychopharmacol Biol Psychiatry. 2013;40:207-12.

25. Tso IF, Carp J, Taylor SF, Deldin PJ. Role of visual integration in gaze perception and emotional intelligence in schizophrenia. Schizophr Bull. 2014:40:617-25.

26. Hurtado MM, Triviño M, Arnedo M, Roldán G, Tudela P. Are executive functions related to emotional intelligence? A correlational study in schizophrenia and borderline personality disorder. Psychiatry Res. 2016;246:84-88.

27. Kun B and Demetrovics Z, 2010. Emotional intelligence and addictions: a systematic review. Subst Use Misuse. 2010;45:113160 . 
28. Tabak NT, Green MF, Wynn JK, Proudfit GH, Altshuler L, Horan WP. Perceived emotional intelligence is impaired and associated with poor community functioning in schizophrenia and bipolar disorder. Schizophr Res. 2015;162:189-95.

29. Palmer BR, Gignac G, Manocha R, Stough C. A psychometric evaluation of the Mayer-Salovey-Caruso Emotional Intelligence Test Version 2.0. Intelligence. 2005;33:285-305.

30. Henry JD, Green MJ, de Lucia A, Restuccia C, McDonald S, O'Donnell M. Emotion dysregulation in schizophrenia: reduced amplification of emotional expression is associated with emotional blunting. Schizophr Res. 2007;95:197-204.

31. Copestake S, Gray NS, Snowden RJ. Emotional intelligence and psychopathy: a comparison of trait and ability measures. Emotion. 2013;13:691-702.

32. Bar-On R. The Bar-On Emotional Quotient Inventory (EQ-i): technical manual. Toronto: Multi-Health Systems; 1997.
33. Salovey P, Mayer JD, Goldman SL, Turvey C, Palfai TP. Emotional attention, clarity, and repair: Exploring emotional intelligence using the trait meta-mood scale. In: Pennebaker JW, editor. Emotion, disclosure, and health. Washington: American Psychological Association; 1995. p. 125-54.

34. Schutte NS, Malouff JM, Hall LE, Haggerty DJ, Cooper JT, Golden $\mathrm{CJ}$, et al. Development and validation of a measure of emotional intelligence. Pers Individ Dif. 1998;25:167-77.

\section{Correspondence:}

Elisa Brietzke

Rua Borges Lagoa, 570, Vila Clementino

04038-000 - São Paulo, SP - Brazil

Tel.: +55 (11) 55764991

E-mail: elisabrietzke@hotmail.com 